Conf-950691--6

UCRL-JC-119194

PREPRINT

$\$$

\title{
Magnet Coil Electrical Gaskets of High Compliance and Ampacity
}

\author{
Arthur R. Harvey and Robert M. Yamamoto
}

This paper was prepared for submittal to the Fourteenth International Conference on Magnet Technology

Tampere, Finland

June 11 - 16, 1995

May 17, 1995

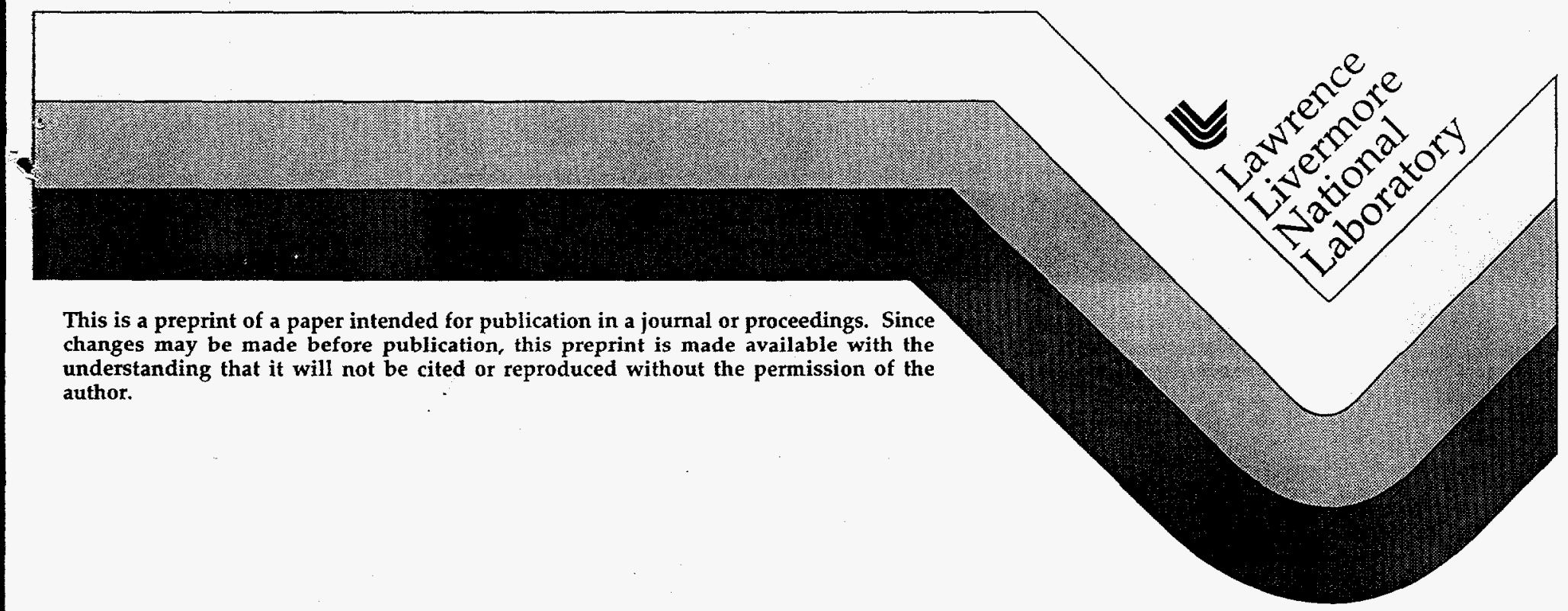




\section{DISCLAIMER}

This report was prepared as an account of work sponsored by an agency of the United States Government. Neither the United States Government nor any agency thereof, nor any of their employees, make any warranty, express or implied, or assumes any legal liability or responsibility for the accuracy, completeness, or usefulness of any information, apparatus, product, or process disclosed, or represents that its use would not infringe privately owned rights. Reference herein to any specific commercial product, process, or service by trade name, trademark, manufacturer, or otherwise does not necessarily constitute or imply its endorsement, recommendation, or favoring by the United States Government or any agency thereof. The views and opinions of authors expressed herein do not necessarily state or reflect those of the United States Government or any agency thereof. 


\section{DISCLAIMER}

Portions of this document may be illegible in electronic image products. Images are produced from the best available original document. 


\title{
Magnet Coil Electrical Gaskets of High Compliance and Ampacity
}

\author{
Arthur R. Harvey, Robert M. Yamamoto \\ Lawrence Livermore National Laboratory, Livermore, CA. USA
}

\begin{abstract}
Coils employed in the magnets of the PHENIX Detector, presently under construction for RHIC (Relativistic Heavy Ion Collider) at the Brookhaven National Laboratory, are massive (weight $\sim 8000 \mathrm{kG}$ each). For that reason we subdivided them into a series of manageable subcoils that we will subsequently boit together. Electrical terminals attached to the subcoils conductors are rigidly embedded and precisely located during vacuum impregnation. However; we anticipate some missalignment and nonuniform gaping to occur between terminals at assembly. We have elected to use electrical gaskets of high compliance and ampacity between the bolted terminals to enhance the current carrying capability of the electrical joints. This paper describes the material candidates selected, the tests performed, and the relative ranking of the materials tested.
\end{abstract}

\section{INTRODUCTION}

Most magnet terminals to power bus connections have some compliance either through the use of flexible power cables or flexible heavy braid power bus connectors. Most conductor hydraulic circuits within a magnet coil are series connected by silver-brazed electrical joints. The physical size and weight of the Phenix magnet coils for $\mathrm{RHIC}^{\prime}$ require that the magnets be subdivided into submagnets of lesser weight (approx. $700 \mathrm{kG}$ for the outer magnet coils) for field assembly. We have elected to bolt these subcoils together. We have also elected to precisely locate and rigidly embed the terminal blocks in the epoxy impregnated subcoils. We anticipate some misalignment of and gapping between the subcoil terminals to occur at assembly. For that reason we inaugurated a search for candidate materials suitable of carrying upwards of 1700 amperes across these joints.

\section{MATERIALS TESTED}

In addition to traditional materials utilized in prior electrical gasket applications, a material (FoamMetal(B) normally used as filtering media was suggested as a candidate material. FoamMetal is a copper, open mesh, sintered material capable of being compressed into a surface conformable sheet when pressed between two plates. Specifically, the following materials and combinations were tested:

- $\quad$ silver plate on the terminal faces (no gasket)

- unplated coarse copper screen

- $\quad$ silver plated and unplated, fine copper screen

- $\quad$ silver plated copper sheet

- $\quad$ silver plated and unplated FoamMetal
- $\quad$ plated FoamMetal paired with plated FoamMetal - $\quad$ plated FoamMetal paired with plated fine screen - $\quad$ plated FoamMetal paired with plated sheet

\section{TESTING APPARATUS}

The testing apparatus is shown in fig. 1. It consisted of two silver plated copper bus bars bolted together with a single, electrically insulated $5 / 8$ in. dia. bolt; a DC power supply (HP 6011A, $0-20 \mathrm{~V}, 0-120 \mathrm{~A}$ ); a Nanovoltmeter (Keithley 181); a thermocouple temperature sensor; coupled with $4 / 0$ power cables and voltage tap cables. The cross-section of the bus bars was selected to minimize the resistance of the bus bars as well as to prevent the bars from deflecting while under load. The single insulated bolt was selected to insure an equal force distribution across the gasket under test and also to prevent current from flowing in the bolt. The voltage taps were spaced 6 in. apart or 3 in. from the bolt in each bar.

\section{TESTS PERFORMED}

The data recorded for all tests included the current applied, the tightened bolt torque setting, the ambient temperature, the sample thickness both before and after the test (with the exception of cycled torques on the same sample), and the voltage reading between the taps. The following tests were performed:

- Cycling of current from an initial value in 10 ampere steps to a peak value followed by a stepwise decent to a terminal value.

- Incremental cycling of torque from a low value of $20 \mathrm{ft}-\mathrm{lb}$ to a peak value of $60 \mathrm{ft}-\mathrm{lb}$ for plated sheet, screen, and FoamMetal.

- An incremental decrease of torque from a peak value of $60 \mathrm{ft}-1 \mathrm{~b}$ to a low value of $30 \mathrm{ft}-\mathrm{lb}$ for the plated FoamMetal sample

Measurements on a FoamMetal sample with an induced taper

- Remeasurement of a sample after a time interval of 3 days (plated screen paired with plated sheet)

\section{DATA ANALYSIS AND REDUCTION}

A typical plot of voltage drop versus current is shown in fig. 2 for one of the samples tested. Clearly, this plot and others similarly constructed are linear for both ascending 


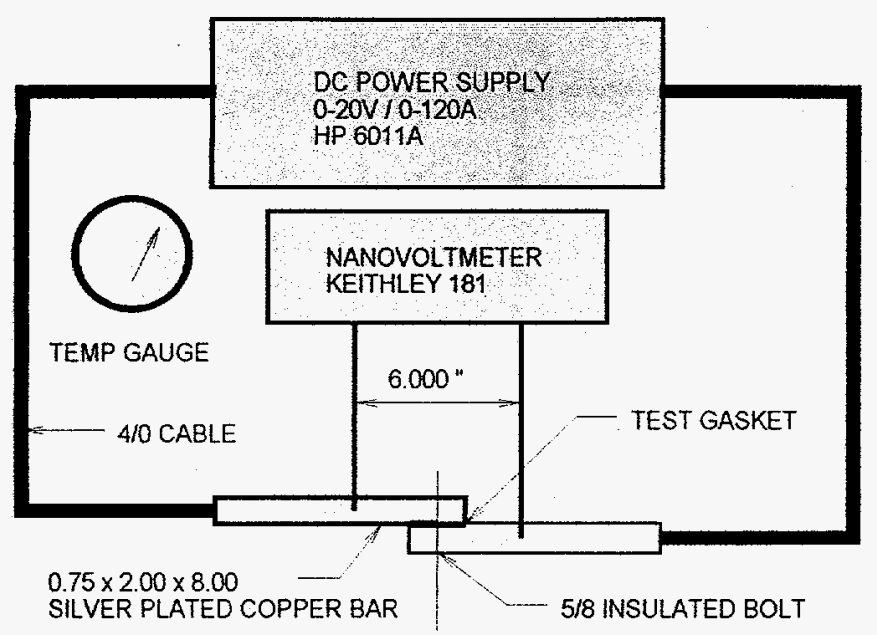

Fig. 1. A schematic layout of the electrical gasket test apparatus.

and descending currents.

The computations for resistance include both the resistance of the bus bars between voltage taps and the sample gasket for each test. A reasonable estimate of the resistance for the bus bars alone is 2.323 microOhms. The joint resistance for each case is then approximately equal to the computed assembly resistance minus the estimated bus bar resistance. The reciprocal of this computed resistance is the approximate joint conductivity.

Table I. lists the sample gaskets and their ID's, material description, torque settings, and conductivities. Some of the samples listed are physically single samples but have different torque settings or were measured on different dates. The samples are listed in descending order of joint conductivity

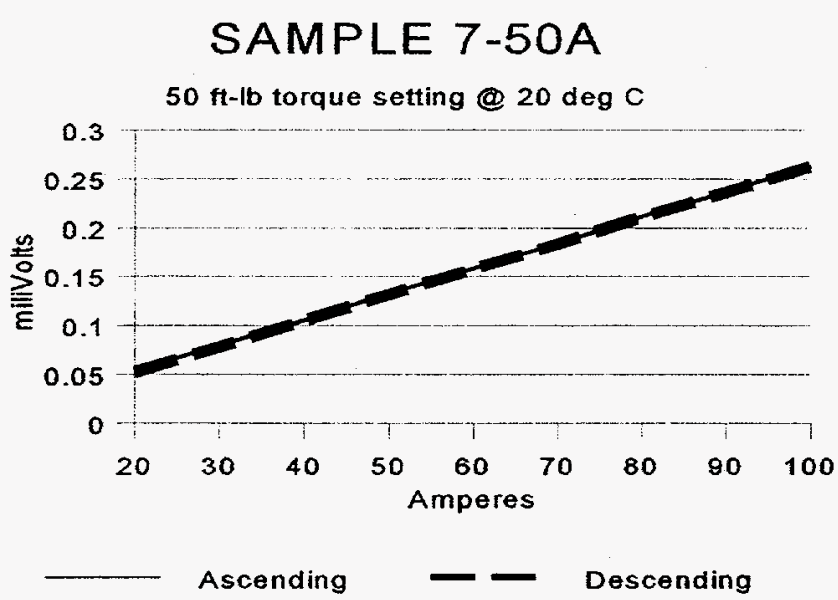

Fig. 2. Typical data plot of voltage drop as a function of current for one of the tested samples.
TABLE I

T EST SAMPLE CONDUCTIVTIES

\begin{tabular}{|c|c|c|c|}
\hline $\begin{array}{l}\text { Sample } \\
\text { ID }\end{array}$ & $\begin{array}{c}\text { Gasket Sample } \\
\text { Material }\end{array}$ & $\begin{array}{c}\text { Torque } \\
\text { ft-lb }\end{array}$ & $\begin{array}{l}\text { Conductivity } \\
\text { megaMho }\end{array}$ \\
\hline $1 \mathbf{A}$ & Plated foam +plated foam & 60 & 3.83 \\
\hline $2 \mathrm{~A}$ & Plated FoamMetal & 50 & 3.60 \\
\hline 3A & Plated FoamMetal & 50 & 3.25 \\
\hline $4 \mathrm{~A}$ & Plated FoamMetal & 60 & 3.23 \\
\hline $5 A$ & Plated FoamMetal & $50^{*}$ & 3.23 \\
\hline $6 \mathrm{~A}$ & Plated FoamMetal & 40 & 2.92 \\
\hline $7 \mathrm{~A}$ & Pl FoamMetal + pl sheet & 60 & 2.91 \\
\hline $8 \mathrm{~A}$ & Plated FoamMetal wedge & 60 & 2.84 \\
\hline $9 \mathrm{~A}$ & Pl FoamMetal + pl screen & 60 & 2.81 \\
\hline $10 \mathrm{~A}$ & Plated FoanMetal & 30 & 2.77 \\
\hline $11 \mathrm{~A}$ & Plated FoamMetal & $40^{*}$ & 2.62 \\
\hline $12 \mathrm{~A}$ & Plated FoamMetal & $30^{*}$ & 2.34 \\
\hline 1D & Unplated FoamMetal & 50 & 2.31 \\
\hline $1 B^{\star *}$ & Pl screen + plated sheet & 60 & 2.20 \\
\hline $2 \mathrm{~B}$ & Plated fine screen & 50 & 2.18 \\
\hline $3 C$ & Plated sheet & 30 & 2.11 \\
\hline 3B & Plated screen + plated sheet & 60 & 2.02 \\
\hline $4 B$ & Plated fine screen & 60 & 1.98 \\
\hline $2 C$ & Plated sheet & 60 & 1.93 \\
\hline $13 \mathrm{~A}$ & Plated FoamMetal & 20 & 1.90 \\
\hline $5 B^{* \bullet}$ & Plated screen + plated sheat & 60 & 1.84 \\
\hline $1 \mathrm{C}$ & Plated sheet & 20 & 1.72 \\
\hline $\begin{array}{ll}4 C \\
6 B\end{array}$ & None & 60 & 1.66 \\
\hline $\begin{array}{l}6 B \\
5 C\end{array}$ & Plated fine screen & 40 & 1.64 \\
\hline 5C & Plated sheet & 50 & 1.64 \\
\hline $\begin{array}{l}78 \\
6 C\end{array}$ & Plated fine screen & 50 & 1.61 \\
\hline $\begin{array}{l}6 \mathrm{x} \\
8 \mathrm{~B}\end{array}$ & Plated sheet & 40 & 1.59 \\
\hline $9 B$ & Plated fine screen & 30 & 1.37 \\
\hline $2 \mathrm{D}$ & Plated fine scroen & 20 & 1.02 \\
\hline $3 \mathrm{D}$ & Unplated ine screen & 50 & 0.88 \\
\hline AD & Unplated coarse sereen & 60 & 0.79 \\
\hline & Unplated fine screen & 50 & 0.40 \\
\hline
\end{tabular}

* Torque reduced trom a higher value

** Same sumple .... Values derived from 133 were 3 dass after those for 513

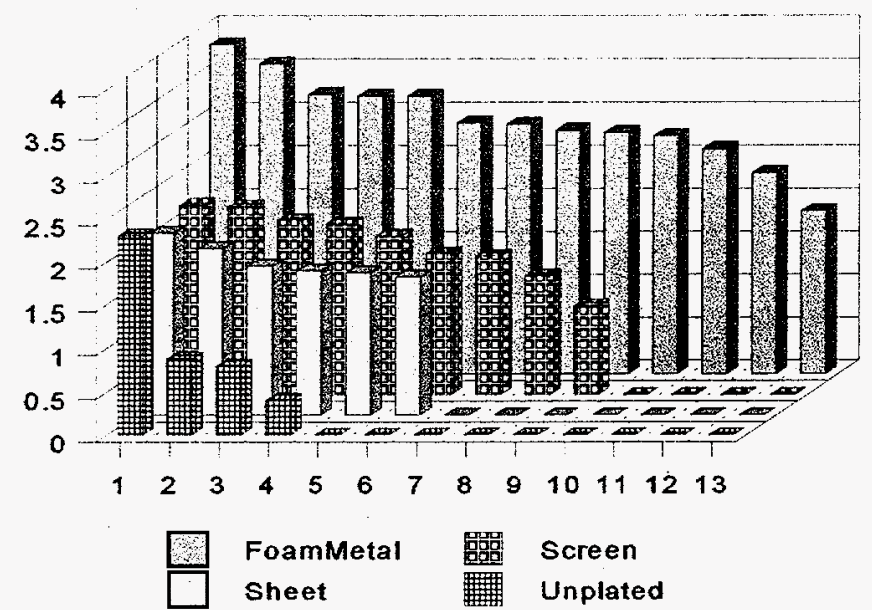

Fig 3. Test sample conductivities grouped by material type. 
Fig. 3 is a plot of the conductivity of the samples listed in the table; but the materials are grouped by type (FoamMetal, screen, sheet, etc.) in descending order. We have grouped all paired material as follows:

- FoamMetal + any other material is grouped with FoamMetal

- Fine screen + sheet is grouped with Screen

- No gasket is grouped with sheet

- All unplated material is grouped together

The sample ID is referenced by the base coordinate grid, i.e., $1 \mathrm{~A}, 3 \mathrm{C}$, etc. which correspond to the sample ID's listed in the table.

From the graph it may be seen that the group containing FoamMetal samples is clearly superior in conductivity ranking to any other grouping. Also with the exception of unplated FoamMetal (sample ID) all of the unplated samples are markedly low. The samples with sheet and fine screen have values that lie between the extremes with no clear indication that one is markedly better than the other:

Fig. 4 is a plot of the conductivity as a function of the bolt torque setting for several tests. It may be observed that the FoamMetal, which is a single sample, increases with increased torque and decreases as the torque is reduced. The conductivities have dropped to 85 to $90 \%$ of the values obtained for the identical torque settings during the initial application. Even so, the FoamMetal conductivity at relaxed joint pressure still exceeds that of any other grouping.

The conductivity versus torque follows a predictable trend for the screen sample. However; the sheet sample is clearly at odds with the expected result (higher conductivity for higher torque).

Sample $8 \mathrm{~A}$ is a FoamMetal gasket which was deliberately compressed into a wedge tapering from 0.015 in. on one edge to $0.010 \mathrm{in}$. on the opposite edge by introducing a $0.013 \mathrm{in}$. thick nonconducting stop on one edge of the clamped joint. Despite the unevenly distributed pressure on the gasket the conductivity of the joint was approximately 2.84 megaMhos as compared to 3.23 megaMhos for an evenly distributed pressure FoamMetal gasket at the same torque setting.

Sample 1B and 5B are the same sample. Electrical tests were performed and recorded for sample $5 B$ on a given date. The same electrical tests were repeated on the unaltered sample 3 days later for which the results are recorded as sample $5 \mathrm{~B}$. The conductivity improved from 1.84 to 2.20 megaMhos.

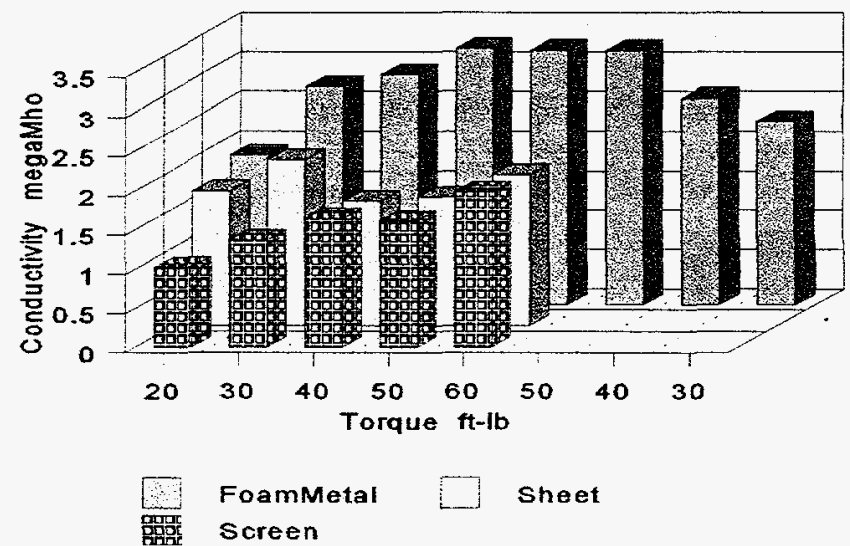

Fig. 4. Test sample conductivitics as a function of torque setting.

\section{OBSERVATIONS AND CONCLUSIONS}

Plated fine wire screen has been used successfully in the past for high current pulsed coils. The screen used in our tests appeared to have oxidized in random locations and patterns during the tests we performed. We believe that initial low torque settings may be responsible for this and also for the relatively poor test results at the higher torque settings that followed.

FoamMetal compressed from an initial thickness of 0.060 in. to a final thickness of $0.013 \mathrm{in.}$ after being subjected to a torque setting of 50 or $60 \mathrm{ft}-\mathrm{lb}$. This material is easily subject to tear prior to being compressed. After compression the tear strength is markedly improved. When FoamMetal is paired with either itself or to fine screen it becomes cladded to the paired material after being compressed. Further, two pieces of FoamMetal paired together produced the highest conductivity of the samples tested. FoamMetal or FoamMetal-Screen-FoamMetal sandwich would appear to provide the best solution for our application.

\section{ACKNOWLEDGMENT}

Mark Fowler and Nate Liggins, LLNL secured and assembled the test apparatus and assisted in the performance of the tests.

\section{REFERENCES}

[1] R. Yamamoto, et. al. "The PHENIX Detector Magnet Subsystem" presented at the Fourteenth International Conference on Magnet Technology, 11 - 16 June 1995, Tampere, Finland

This work was performed under the auspices of the U.S. Department of Energy by the Lawrence Livermore National Laboratory under contract No. W-7405-Eng-48 